\title{
Effects of Early, Non-Excisional Debridement in the Operating Theatre on Paediatric Burn Wound Re- Epithelialisation Time and Skin-Graft Requirement: A Retrospective Cohort Study.
}

Bronwyn Griffin ( $\square$ bronwyn.griffin@griffith.edu.au )

Griffith University https://orcid.org/0000-0002-6182-9125

\section{Anjana Bairagi}

Queensland University of Technology IHBI: Queensland University of Technology Institute of Health and Biomedical Innovation

\section{Lee Jones}

Queensland University of Technology IHBI: Queensland University of Technology Institute of Health and Biomedical Innovation

\section{Zoe Dettrick}

Queensland University of Technology IHBI: Queensland University of Technology Institute of Health and Biomedical Innovation

\section{Maleea Holbert}

Queensland Children's Hospital

\section{Roy Kimble}

Queensland Children's Hospital

\section{Research article}

Keywords: Non-excisional debridement, Burn, Children, Split-thickness skin graft, Re-epithelialisation, General anaesthesia

Posted Date: August 9th, 2021

DOl: https://doi.org/10.21203/rs.3.rs-775872/v1

License: (9) This work is licensed under a Creative Commons Attribution 4.0 International License. Read Full License 


\section{Abstract}

Background: Reported advantages of early excision and grafting for larger burn injuries include reduced morbidity, mortality, and hospital length of stay for adult burn patients. Evidence to support this has strengthened over the last 50 years. However, a paucity of evidence supports the best option for paediatric burns and, less still, the advantages of non-excisional (mechanical) debridement. Ketamine procedural sedation and analgesia in the emergency department is a popular alternative to debridement in operating theatres under general anaesthesia. This study aims to evaluate the association between early (<24hours post injury) non-excisional debridement under general anaesthesia in the operating theatre with burn wound re-epithelialisation time and skin graft requirements.

Methods: Children younger than 17 years who presented with burns of five percent total body surface area or greater were included in a retrospective cohort study. Data between January 2013 to December 2019 were extracted from a state-wide paediatric burns' registry for analysis. Time to re-epithelialisation was tested using survival analysis, and binary logistic regression for odds of skin graft requirement. A propensity matched dataset based on depth and size of burn wound, was used to analyse effects of early non-excisional debridement in the operating theatre compared to control.

Results: Overall, 392 children met eligibility for the study with a male over-representation of $58.2 \%$. When propensity matched, non-excisional debridement under general anaesthesia in the operating theatre, within 24hours of injury, significantly reduced the time to re-epithelialisation (15.0 (Cl: 11.00-20.00) versus 20.0 (Cl:13.5 - 31.00) days) and the odds of requiring a skin graft (OR:0.319 $(0.125-0.812)$.

Conclusion: This study is the first to demonstrate that early, initial, non-incisional debridement under general anaesthesia in the operating theatre significantly reduces wound re-epithelialisation time and subsequent need for a skin graft in paediatric burn patients. Analysis suggests that ketamine procedural sedation in the emergency department used for burn wound debridement is not an effective substitute for debridement in the operating theatre.

\section{Introduction}

Significant advances in the survival of paediatric patients with medium to large burn wounds ( $>5 \%$ total body surface area (TBSA)), were made in the 20th century(1-3). Sepsis, skin grafting requirements, wound re-epithelialization time have become key clinical outcomes to improve burn wound care beyond survival in developed countries. Following a thermal injury, the compromised barrier function of the skin combined with the anatomical characteristics of paediatric skin, render children more susceptible to 
inflammation and infection (4). The aim of debridement is to remove all non-viable tissue and debris from the injured cutaneous surface. Traditional surgical debridement, using sharp excision, aimed to improve survival by avoiding sepsis, however the sacrifice with this method is the unintentional removal of healthy tissue along with the intentional removal of dead tissue. Non-excisional debridement methods include mechanical (e.g. hydro surgery or abrasion technique) and more recently, enzymatic debridement $(5,6)$. Mechanical debridement requires an aggressive scrub using gauze, non-cytotoxic cleanser, and water. Once completed, a more accurate assessment of the size and depth of the burn wound is possible, critical considerations of burn management, which can expedite wound closure, the hallmark of effective burn management(7).

Many studies have demonstrated that, delayed burn wound re-epithelialisation is associated with an increased risk for hypertrophic scar formation in children(8-10). Multiple factors have been found to influence this critical time to re-epithelialization time in children. Hence, clinicians consider the timing, setting and analgesia at initial debridement of medium to large burn wounds to optimise outcomes such as re-epithelialisation time and requirement for skin graft. Time to wound debridement is dependent on the consideration of a multitude of factors including patient stability, severity, body location and TBSA(11). Early debridement is thought to reduce the toxic and bacterial burden from a burn wound(1214 ) and within 24 hours of injury has been associated with significantly reduced re-epithelialisation time in adults (15). In children, early excision with immediate wound closure was associated with improved survival, shorter hospitalisation $(3,13,16)$ and found to be safe and effective within 72 hours of injury $(1)$. In the study site, a quaternary paediatric hospital and burns centre, greater than 20,000 paediatric burns patients have been treated over the last 20 years with only two children succumbing to their injuries.

Furthermore, there are several factors in the consideration for early debridement including burn severity, staff expertise, available resources, location, and type of analgesia that will be administered. Sub-optimal pain management has been shown to delay paediatric burn wound re-epithelialisation(17). In addition, a recent study reported that parental acute psychological distress influences child procedural-related pain distress(18). Often, minor (TBSA $<5 \%$ ), and a proportion of medium to large TBSA burns, are initially managed in the emergency department (ED) with procedural sedation and analgesia (PSA). The level of PSA ranges from minimal (anxiolysis with impaired cognitive function) to moderate, where the child would have reduced level of consciousness, respond to verbal commands and maintain adequate spontaneous ventilation $(19,20)$. The resurgence of paediatric PSA with ketamine, either as a single drug or in combination with other PSA agents (21) is due to its potent anaesthetic and analgesic properties and low incidence cardiorespiratory adverse effects(22-27) when compared to opioids. For these reasons, ketamine PSA is a popular choice by clinicians treating paediatric burns wounds in EDs $(21,28-$ 30). Despite this, 'emergence reaction' after ketamine is a well-documented adverse reaction. The rate of hallucination when emerging from a dissociative state occurs at rates between $5-14 \%(31)$, and is reported to be transient and mild in children(32). However, little is known on the efficacy of longer term protective factors of medical trauma. 
This study aims to evaluate the effect of non-excisional, mechanical debridement within 24 hours of paediatric burns injuries greater than or equal to $5 \%$ TBSA, under general anaesthesia in the operation theatre on wound re-epithelialisation and skin graft requirements.

\section{Objectives}

The objectives of this study were as follows:

1. Primary. The effect of timing, setting and analgesia for non-excisional debridement of acute, medium to large ( $\geq 5 \%$ TBSA), paediatric burn injuries on time to re-epithelialisation.

2. Secondary. The effect of timing, setting and analgesia for non-excisional debridement of acute, medium to large ( $>5 \%$ TBSA), paediatric burn injuries on skin graft requirements.

\section{Methods}

A single-centre, retrospective, cohort study using prospectively collected data from the (De-identified) Paediatric Burns Registry was conducted at a paediatric burn's referral centre in (De-identified), Australia. All children who presented to the study site, between January 2013 - December 2019, younger than 17 years, with TBSA $\geq 5 \%$, of any burn mechanism were eligible for inclusion. Parents who declined for their child's data to be entered into the Paediatric Burns Registry were excluded from this study.

All children taken to theatre within 24-hours post-burn for an initial, non-excisional debridement in theatre received general anaesthesia. The non-excisional debridement intervention uses an aggressive washing technique with sterile water, soap-free surfactant cleanser (QV Cleanser, Melbourne, Australia) (33), and sterile gauze sponge (Ray-Tec, Johnson \& Johnson, NJ, USA) for the removal of all non-viable tissue from the burn wound. This was followed by immediate wound closure with an appropriate cover such as a silver impregnated, or biological dressing as determined by the treating surgeon. Children were then subsequently managed as either in-patient or outpatients, dependent on the severity of burn injury or other concern. The treating burns surgeon determined when burn wound achieved spontaneous reepithelialisation $\geq 95 \%$ or requirement for a skin graft.

\section{DATA MANAGEMENT}

Data for each patient was extracted from the (De-identified) Paediatric Burns Registry and included sociodemographic data, TBSA\%, burn depth, age of burn in hours at debridement, initial dressing applied, analgesia at debridement, setting of initial debridement, time to re-epithelialisation in days and incidents of skin graft requirements. Data collection was from the time of first presentation to a health service, up until wound re-epithelialisation was achieved or skin grafting undertaken. Data was captured with and stored in FileMaker (Claris International Inc., NSW, Australia).

\section{STATISTICAL METHODS}


Demographic data was summarised and tabulated. Categorical variables were represented as a number with frequencies and continuous, non-parametric variables as median with interquartile range (IQR). Factors that confound burn severity (burn depth, TBSA\%) and are known to influence burn wound reepithelialisation and requirement for grafting were controlled for during statistical analysis. The timing, location and analgesia at initial wound debridement were selected as the outcome variable for this investigation, with the dependent variables being time to re-epithelialisation and need for grafting. For the primary analysis (Scenario 1), the dataset was divided into two groups: OT < 24hrs (intervention) and 'Other settings' (comparator). The intervention group (OT<24hrs) included paediatric burn patients taken to OT for non-excisional wound debridement under general anaesthetic within the first 24-hours following burn injury. The 'Other settings' group included all debridement that were not completed in the operation theatre under general anaesthesia within 24 hours of injury. For the sub-analysis (Scenario 2), children whose debridement were completed in the ED with ketamine PSA (ED Ketamine) were selected as a subset from the 'Other settings' group for comparison with the OT < 24hrs (intervention) group.

For scenario 1, injury severity (burn depth and TBSA\%) was used for propensity matched scores (PSM). Kaplan Meier analysis was then performed to examine the influence of acute non-excisional burn wound debridement in the OT on wound time to re-epithelialisation in median (95\% Confidence Interval) days for each group.

To complete the sub-analysis (Scenario 2) for the primary outcome, the low count of PSA (ED Ketamine) events deemed it unfeasible to perform propensity matched scores. Hence, a Cox proportional hazards model was used to examine the associations between setting, timing, and analgesia at initial debridement with wound re-epithelialisation time adjusted for burn severity using TBSA and burn depth. Binary logistic regression was used to determine the associations between setting, timing, and analgesia at initial debridement with requirement for skin graft using PSM data for Scenario 1 and unmatched data for Scenario 2. The timing of skin graft is commonly influenced by factors not directly related to the injury(34). After consultation with the study centre burn surgeons, a dummy value of 28 days was used to estimate spontaneous re-epithelialisation, as this represents an average of the longest time surgeons would wait before skin grafting. A value of $p<0.05$ was considered statistically significant. Data was analysed with SPSS 27(IBM Corporation, Armonk, NY, USA) software.

\section{Results}

\section{PARTICIPANTS}

Three hundred and ninety-four paediatric burn patients met the inclusion criteria for the study (i.e., aged $\leq 17$ years with a burn TBSA $\geq 5 \%$ ) and were extracted from the (De-identified) Paediatric Burns Registry. Once burn depth and TBSA were inserted in the propensity-matched score model, $N=121$ cases were matched and subsequently analysed. Demographic details of the sample population are presented below 
in Table 1. Children under the age of four accounted for $68 \%$ of participants included in this investigation. Males were overrepresented in the sample population - accounting for more than $54 \%$ of children overall. For paediatric burn patients not taken to theatre for debridement under general anaesthesia, more than $50 \%$ received burn wound debridement at the tertiary Children's Hospital, ED. 
Table 1

Characteristics of patients taken to theatre for non-excisional debridement within 24 hours and those debrided in the Other settings (Scenario 1 - Propensity matched).

\begin{tabular}{|c|c|c|}
\hline & $\begin{array}{l}\text { OT }<24 \mathrm{hrs} \\
\mathrm{n}=68\end{array}$ & $\begin{array}{l}\text { Other Settings } \\
\mathrm{n}=54\end{array}$ \\
\hline \multicolumn{3}{|l|}{ Age (Years) } \\
\hline $0-4$ & $44(64.7)$ & \multirow{3}{*}{$\begin{array}{l}39(72.2) 8 \\
(14.8) \\
7(13.0)\end{array}$} \\
\hline $5-10$ & $13(19.1)$ & \\
\hline$>10$ & $11(16.2)$ & \\
\hline GENDER, M:F n(\%) & $\begin{array}{l}36(52.9): \\
30(44.1)\end{array}$ & $\begin{array}{l}30(55.6): \\
24(44.4)\end{array}$ \\
\hline TBSA ,\% Median (IQR) & $\begin{array}{l}12.0(8.00- \\
20.00)\end{array}$ & $\begin{array}{l}10.00(6.00- \\
15.00)\end{array}$ \\
\hline \multicolumn{3}{|l|}{ BURN DEPTH, n(\%) } \\
\hline Full thickness & $25(36.8)$ & $15(27.8)$ \\
\hline Deep partial thickness & $33(48.5)$ & $27(50.0)$ \\
\hline Superficial partial thickness & $10(14.7)$ & $12(22.2)$ \\
\hline Recieved Appropriate First Aid, n(\%) & $44(64.7)$ & $38(70.4)$ \\
\hline \multicolumn{3}{|l|}{ INITIAL DRESSING, n(\%) } \\
\hline Acticoat & $2(2.9)$ & $8(14.8)$ \\
\hline Acticoat + Mepitel & $45(66.2)$ & $23(42.6)$ \\
\hline Mepilex Ag & $5(7.4)$ & $13(24.1)$ \\
\hline Combined Silver** & $2(2.9)$ & $5(9.3)$ \\
\hline Biobrane ${ }^{\circledR}$ and/or RECELL ${ }^{\circledR}$ & $14(20.6)$ & - \\
\hline $\begin{array}{l}\text { Occasions of operating theatre for General Anaesthesia per } \\
\text { patient, Median(IQR) }\end{array}$ & $\begin{array}{l}4.00(1.00- \\
7.00)\end{array}$ & $\begin{array}{l}2.00(0.00- \\
5.00)\end{array}$ \\
\hline Requirement for Skin Graft, n(\%) & $29(42.6)$ & $28(51.9)$ \\
\hline Time to re-epithelialistaion, days, Median $(95 \% \mathrm{Cl})$ & $\begin{array}{l}15.0(11.00- \\
20.00)\end{array}$ & $\begin{array}{l}20.0(13.5- \\
31.00)\end{array}$ \\
\hline
\end{tabular}


Table 2

Characteristics of patients taken to theatre for non-excisional debridement within 24 hours and those debrided in ED under Ketamine PSA

\begin{tabular}{|c|c|c|}
\hline & $\begin{array}{l}\text { OT }<24 \mathrm{hrs} \\
\mathrm{n}=70\end{array}$ & $\begin{array}{l}\text { ED_Ketamine } \\
\mathrm{n}=\mathbf{3 1}\end{array}$ \\
\hline AGE, years Median(IQR) & $\begin{array}{l}2.00(1.00- \\
5.00)\end{array}$ & $2.00(1.00-6.00)$ \\
\hline GENDER, M:F n(\%) & $\begin{array}{l}40(57.1): \\
28(40.0)\end{array}$ & $17(54.8): 14(45.2)$ \\
\hline TBSA ,\% Median (IQR) & $\begin{array}{l}12.0(8.00- \\
19.25)\end{array}$ & $\begin{array}{l}11.00(7.00- \\
14.00)\end{array}$ \\
\hline \multicolumn{3}{|l|}{ BURN DEPTH, n(\%) } \\
\hline Full thickness & $24(34.3)$ & $8(25.8)$ \\
\hline Deep partial thickness & $34(48.6)$ & $15(48.4)$ \\
\hline Superficial partial thickness & 12(17.1) & $8(25.8)$ \\
\hline Recieved Appropriate First Aid, n(\%) & $45(64.3)$ & $23(74.2)$ \\
\hline \multicolumn{3}{|l|}{ INITIAL DRESSING, n(\%) } \\
\hline Acticoat & $2(2.9)$ & $1(3.2)$ \\
\hline Acticoat + Mepitel & $47(67.0)$ & $17(54.8)$ \\
\hline Mepilex Ag & $4(5.7)$ & $9(29.0)$ \\
\hline Combined Silver** & $2(2.94)$ & $2(6.5)$ \\
\hline Biobrane ${ }^{\circledR}$ and/or RECELL ${ }^{\circledR}$ & 13(18.6) & - \\
\hline $\begin{array}{l}\text { Occasions of operating theatre for General Anaesthesia per } \\
\text { patient, Median(IQR) }\end{array}$ & $\begin{array}{l}3.00(1.00- \\
5.25)\end{array}$ & $3.00(1.00-5.00)$ \\
\hline Requirement for Skin Graft, n(\%) & $27(38.6)$ & $17.0(54.8)$ \\
\hline $\begin{array}{l}\text { Time to re-epithelialistaion, days } \\
\text { Median }(95 \% \mathrm{Cl})\end{array}$ & $\begin{array}{l}22.0(14.02- \\
29.97)\end{array}$ & $\begin{array}{l}30.0(21.97- \\
38.04)\end{array}$ \\
\hline Median(95\%Cl) & & \\
\hline \multicolumn{3}{|c|}{$\begin{array}{l}\text { LEGEND: OT = operating theatre, } N=\text { number of participants, TBSA }=\text { total body surface area burned, } \\
\text { IQR = interquartile range, ED = Emergency Department, } G A=\text { general anaesthesia, } P S A=\text { procedural } \\
\text { sedation and analgesia, } M=\text { Male, } F=\text { Female, } C l=\text { confidence interval, } *=p<0.001 \text {, ** Combined } \\
\text { Silver = Acticoat + Mepilex Ag, }\end{array}$} \\
\hline
\end{tabular}

\section{Effect of non-excisional debridement on time to re- epithelialisation}


SCENARIO 1 (OT < 24hrs vs Other Setting): A significant difference in time to re-epithelialisation was identified between paediatric patients taken to theatre within 24 hours in comparison to those debrided in the ED or OT outside 24-hours ( $p=0.043$ ). Median time to re-epithelialisation for children taken to theatre for debridement under general anaesthetic was 15 days $(95 \% \mathrm{Cl} 12.977-17.023)$ versus 20 days $(95 \% \mathrm{Cl}$ 16.263-23.737) for patients debrided in the ED or OT outside 24-hours post-burn, Fig. 1.

SCENARIO 2 (OT < 24hrs vs ED Ketamine): Median time to re-epithelialisation for children taken to theatre for debridement under general anaesthetic was 22.0 days $(95 \% \mathrm{Cl} 14.02-29.97)$ versus 30.0 days $(95 \% \mathrm{Cl}$ 21.97-38.04) for children debrided in ED under ketamine PSA. The Cox regression demonstrated that in a multivariable analysis, there was a significant effect of the setting of the initial non-excisional debridement of burn injuries (ED Ketamine Hazards Ratio $=0.288,95 \% \mathrm{Cl}: 0.156-0.535, \mathrm{p}<0.001$ ) on burn wound time to re-epithelialisation, in children who underwent non-excisional debridement in under ketamine PSA in the ED when compared to non-excisional debridement under general anaesthetic in theatre within 24 hours of injury, Fig. 2. Full thickness burn depth and TBSA also demonstrated a significant effect $(p<0.001)$ on time to re-epithelialisation. In this scenario, deep partial thickness did not have a significant effect on re-epithelialisation time $(p<0.102)$.

\section{Effect of non-excisional debridement on requirement for skin graft}

SCENARIO 1 (OT< 24hours vs Other Setting): Paediatric patients taken to the operating theatre for nonexcisional wound debridement within 24-hours post-burn were found to have decreased odds of requiring a split thickness graft (Table 3), even after controlling for variables known to influence rates of grafting such as burn depth and TBSA\% (OR 0.32, $\mathrm{Cl} 0.125-0.812, \mathrm{p}=0.016)$. Children taken to theatre within 24hours post-burn for initial debridement had a $68 \%$ decrease in odds of grafting compared to children whose initial debridement was in the ED or in the OT outside 24-hours.

Table 3. Odds of grafting following non-excisional debridement in theatre within 24 hours versus other settings

\begin{tabular}{|llll|}
\hline Variable & Sub-group & Odd Ratio $(95 \%$ Cl) & P value \\
\hline Burn Depth & FT & $28.175(5.858-135.511)$ & $<0.001$ \\
& DPT & $4.956(1.235-19.897)$ & 0.024 \\
& SPT & $* 1$ (reference) & - \\
\hline TBSA & & $1.09(1.017-1.169)$ & 0.015 \\
\hline Non-Excisional Debridement & Other Setting & $0.319(0.125-0.812)$ & 0.016 \\
& OT $<24 \mathrm{hrs}$ & $* 1$ (reference) & - \\
\hline
\end{tabular}


LEGEND: * 1 = reference group for logistic regression,

SCENARIO 2 (OT < 24hours vs ED Ketamine): The odds for requirement of split thickness skin graft were significantly increased in children who underwent non-excisional debridement in in ED under ketamine sedation (ED Ketamine Odds Ratio $=4.696,95 \% 1.573-14.022, p=0.006$ ) than for non-excisional debridement under general anaesthesia within 24hrs of injury when adjusted for full thickness burn depth $(p<0.001)$ and TBSA $(p=0.009)$. Deep partial thickness burn depth did not have a significant effect on the requirement for skin graft $(p=0.060)$, Table 4 .

Table 4. Odds of grafting following non-excisional debridement in theatre within 24 hours versus in the ED under ketamine sedation/analgesia

\begin{tabular}{|llll|}
\hline Variable & Sub-group & Odd Ratio $(95 \% \mathrm{Cl})$ & P value \\
\hline Burn Depth & FT & $20.787(3.992-108.238)$ & $<0.001$ \\
& DPT & $4.042(0.943-17.331)$ & 0.060 \\
& SPT & $* 1$ (reference) & - \\
\hline TBSA & & $1.112(1.027-1.204)$ & 0.009 \\
Non-Excisional Debridement & ED Ketamine & $4.696(1.573-14.022)$ & 0.006 \\
& OT $<24 \mathrm{hrs}$ & $* 1$ (reference) & - \\
\hline
\end{tabular}

LEGEND: * 1 = reference group for logistic regression,

\section{Discussion}

This study is the first to demonstrate that early initial, non-excisional debridement of acute paediatric burns under general anaesthesia in an operating theatre, significantly reduces the wound reepithelialisation time and subsequent requirements for skin graft. Non-excisional burn wound debridement completed within 24 hours of burn injury resulted in a wound re-epithelialisation time of 5 days faster when compared to other settings and 8 days faster when compared to ketamine PSA in the ED. The odds for requiring a skin graft were significantly increased when non-excisional debridement was not completed in theatre under general anaesthetic within 24 hours of injury. These findings add to the evidence supporting early debridement of acute burn injuries in children $(3,12,35,36)$.

The evolution and improvements of paediatric burn care have been reflected by an exceptional increase in survival rates over the last 50 years. Thus, expanding the focus of burn care to decreasing the risk of scar formation. Chipp et al. demonstrated the linear relationship between time to re-epithelialisation and risk of scaring with every additional day taken to re-epithelialise, multiplying the risk of hypertrophic 
scaring by $1.138(10)$. In addition to this Chipp et al. challenged traditional dogma of healing within 3 weeks to be oversimplified in the paediatric cohort, emphasizing that every effort should be made to reach re-epithelialisation as quickly as possible(10).

The initial phase of burn wound healing is typified by inflammation and haemostasis that confine the extent of injury and cleanse the wound(37). Burn wound conversion causes deepening of the burn wound due to ongoing ischaemia and inflammation(38). Early tangential excision is thought to address this inflammatory phase by removal of non-viable tissue from the wound, first described by Janzekovic in 1970(39). Lu et al. 2005 demonstrated the influence of tangential excision within 24 hours post-burn injury of deep partial wounds was a significant reduction of inflammatory markers (IL8, MPO and MDA) when compared non-debrided areas of the wound(14). We hypothesise that non-excisional debridement, in comparison to excisional debridement, is likely to preserve more healthy tissue and contribute to the removal of the considerable burden of these inflammatory markers.

In the ED, wound debridement may occur with the parent present during the procedure. Some parents find this observation and scenario distressing. There is evidence to support that parental distress and anxiety directly correlates to the child's healing time $(40,41)$. It is postulated that general anaesthesia in the operation theatre provides an environment for complete burn wound debridement, adequate wound closure, and optimal peri-procedural analgesia. Traditionally, clinicians have been reluctant to subject young children to frequent general anaesthesia due to concerns for neurotoxicity after exposure to anaesthetic drugs $(42,43)$. Recently, three large paediatric studies (GAS(44), PANDA(45), and MASK (46)) have identified no correlation between single anaesthesia exposure and reduced cognition(43). Whilst this is a promising finding for the safety of children, limited research has been conducted examining the influence of debridement setting and analgesia within 24 hours of injury on clinical outcomes such as reepithelialisation time and skin graft requirements for medium to large burns.

Debridement under general anaesthesia provides a controlled environment where peri-procedural analgesia can be optimised. Brown et al. (2014) showed that wound re-epithelialisation was delayed by $2.2 \%$ for every increase of one point on the Faces Pain Scale- Revised(17).It is postulated that whilst under a general anaesthetic, the injured child is not able to formulate a memory of a painful procedure that may contribute towards increased anticipatory distress(47) during subsequent dressing changes. Further studies would be required to explore this hypothesis. Another proposed benefit of general anaesthesia for initial debridement is that burn surgeons can select the most appropriate wound management approach and achieve complete coverage of the burn wound. This is not always possible in a busy emergency department, for a child who has been given peri-procedural analgesia with or without adjunct distraction techniques.

Efforts to address the complex physiological activity of an acute burn injury, specifically to disrupt wound progression, are increasingly visible in scientific burns literature. The early application of negative pressure wound therapy in paediatric burn wounds has shown decreased time to re-epithelialisation, with suggested cost savings due to decreased proportions of skin grating requirements(34). Additionally, 
effective adherence to 20 minutes of cool running water within the first three hours of burn injury has resulted in significantly reduced odds of skin grafting amongst other patient outcomes(48, 49). More recently Holbert et al. highlighted the characteristics of burn wounds associated with higher pain levels(50). Acknowledging the impact risk factors and interventions have on the time to reepithelialisation and subsequent risk of scarring are important considerations in tailoring acute burn treatment pathways. Bundling these individual interventions together may lead to amplified beneficial patient outcomes. More studies would be necessary to explore this hypothesis.

There were a few limitations of this study. Firstly, the observational data set is at risk of selection bias that is associated with restricting the analysis to participants with completed data for outcomes.

Secondly, although detailed training was provided for data collectors, we cannot eliminate the possibility of variability in data entry into the proformas.

\section{Conclusion}

Early non-excisional debridement of acute burns under general anaesthesia in children reduces wound reepithelialisation time and requirements for skin grafting. Effective non-excisional debridement can be achieved with general anaesthesia, aggressive mechanical debridement with warm water, sterile surgical gauze, and a soap-free surfactant cleanser.

\section{Abbreviations}

\section{TBSA}

Total body surface area

$\mathrm{Cl}$

Confidence interval

IQR

Inter-quartile range

$\mathrm{OR}$

Odds ratio

FT

Full thickness

DDPT

Deep dermal partial thickness

SPT

Superficial partial thickness

\section{Declarations}

Acknowledgments 
The investigators would like to thank the participants and their families as well as the clinical staff of the study site for their continued support.

Funding: This project is unfunded. Dr Griffin is a Senior Research Fellow, funded by the National Health Medical Research Council (Australia), Centre of Research Excellence in Wiser Wound Care (APP1196436).

Availability of data and materials: Not applicable

Ethics approval and consent to participate: The study was approved by the Children's Health Service District-Human Research Ethics Committee (HREC/16/QRCH/61).

Competing interests: No authors have conflicts or competing interests to declare

Consent for publication: Consent for inclusion in the database was obtained at data collection. Patient information was deidentified while undergoing statistical analysis, maintaining patient privacy and confidentiality.

\section{Authors' contributions}

BG, RK and AB collectively developed the concept and protocol for this study. ZD and LJ are both biostatisticians that led the statistical methodology and analysis. MH assisted with data analysis and drafting of manuscript. All authors participated in the drafting up of the manuscript.

\section{References}

1. Herndon DN, Parks DH. Comparison of serial debridement and autografting and early massive excision with cadaver skin overlay in the treatment of large burns in children. J Trauma. 1986;26(2):149-52.

2. Janzekovic $Z$. A new concept in the early excision and immediate grafting of burns. The journal of trauma. 1970;10(12):1103-8.

3. Tompkins RG, Remensnyder JP, Burke JF, Tompkins DM, Hilton JF, Schoenfeld DA, et al. Significant reductions in mortality for children with burn injuries through the use of prompt eschar excision. Ann Surg. 1988;208(5):577-85.

4. Kong F, Galzote C, Duan Y. Change in skin properties over the first 10 years of life: a cross-sectional study. Arch Dermatol Res. 2017;309(8):653-8.

5. Edmondson SJ, Ali Jumabhoy I, Murray A. Time to start putting down the knife: A systematic review of burns excision tools of randomised and non-randomised trials. Burns. 2018;44(7):1721-37.

6. Wormald JC, Wade RG, Dunne JA, Collins DP, Jain A. Hydrosurgical debridement versus conventional surgical debridement for acute partial-thickness burns. Cochrane Database Syst Rev. 2020;9:CD012826.

7. Williams FN, Lee JO. Pediatric Burn Infection. Surg Infect (Larchmt). 2021;22(1):54-7. 
8. Deitch EA, Wheelahan TM, Rose MP, Clothier J, Cotter J. Hypertrophic burn scars: analysis of variables. J Trauma. 1983;23(10):895-8.

9. Lonie S, Baker P, Teixeira RP. Healing time and incidence of hypertrophic scarring in paediatric scalds. Burns. 2017;43(3):509-13.

10. Chipp E, Charles L, Thomas C, Whiting K, Moiemen N, Wilson Y. A prospective study of time to healing and hypertrophic scarring in paediatric burns: every day counts. Burns Trauma. 2017;5(1):3.

11. Daugherty THFMDMS, Ross AMD, Neumeister MWMDF. Surgical Excision of Burn Wounds. Clin Plast Surg. 2017;44(3):619-25.

12. Wilder D, Rennekampff HO. Debridement of burn wounds - Rationale and options. Handchir Mikrochir Plast Chir. 2007;39(5):302-7.

13. Ong YS, Samuel M, Song C. Meta-analysis of early excision of burns. Burns. 2006;32(2):145-50.

14. Lu SL, Liao ZJ, Xiang J, Wang ZY, Yang LY, Jin SW, et al. [Influence of tangential excision within 24 postburn hours on the local wound inflammatory response in patients with deep partial thickness burn]. Zhonghua Shao Shang Za Zhi. 2005;21(1):24-6.

15. Shao F, Ren WJ, Meng WZ, Wang GZ, Wang TY. Burn Wound Bacteriological Profiles, Patient Outcomes, and Tangential Excision Timing: A Prospective, Observational Study. Ostomy Wound Manag. 2018;64(9):28-36.

16. Burke FJ, Bondoc CC, Quinby CW. PRIMARY BURN EXCISION AND IMMEDIATE GRAFTING: A METHOD SHORTENING ILLNESS. The Journal of Trauma: Injury Infection Critical Care. 1974;14(5):389-95.

17. Brown NJ, Kimble RM, Gramotnev G, Rodger S, Cuttle L. Predictors of re-epithelialization in pediatric burn. Burns. 2014;40(4):751-8.

18. Brown EA, De Young A, Kimble R, Kenardy J. Impact of Parental Acute Psychological Distress on Young Child Pain-Related Behavior Through Differences in Parenting Behavior During Pediatric Burn Wound Care. J Clin Psychol Med Settings. 2019;26(4):516-29.

19. Meredith JR, O'Keefe KP, Galwankar S. Pediatric procedural sedation and analgesia. J Emerg Trauma Shock. 2008;1(2):88-96.

20. Ramalho CE, Bretas PMC, Schvartsman C, Reis AG. Sedation and analgesia for procedures in the pediatric emergency room. J Pediatr (Rio J). 2017;93(Suppl 1):2-18.

21. Brunette KE, Anderson BJ, Thomas J, Wiesner L, Herd DW, Schulein S. Exploring the pharmacokinetics of oral ketamine in children undergoing burns procedures. Paediatr Anaesth. 2011;21(6):653-62.

22. Reynolds S. Ketamine. Not Just for Pediatric Sedation? Clinical Pediatric Emergency Medicine. 2017;18(4):286-91.

23. Bellolio MF, Puls HA, Anderson JL, Gilani WI, Murad MH, Barrionuevo P, et al. Incidence of adverse events in paediatric procedural sedation in the emergency department: a systematic review and meta-analysis. BMJ Open. 2016;6(6):e011384. 
24. Mahajan C, Dash HH. Procedural sedation and analgesia in pediatric patients. J Pediatr Neurosci. 2014;9(1):1-6.

25. Bredmose PP, Grier G, Davies GE, Lockey DJ. Pre-hospital use of ketamine in paediatric trauma. Acta Anaesthesiol Scand. 2009;53(4):543-5.

26. Graudins A, Meek R, Egerton-Warburton D, Oakley E, Seith R. The PICHFORK (Pain in Children Fentanyl or Ketamine) trial: a randomized controlled trial comparing intranasal ketamine and fentanyl for the relief of moderate to severe pain in children with limb injuries. Ann Emerg Med. 2015;65(3):248-54. e1.

27. Oliveira JESL, Lee JY, Bellolio F, Homme JL, Anderson JL. Intranasal ketamine for acute pain management in children: A systematic review and meta-analysis. Am J Emerg Med. 2020;38(9):1860-6.

28. Norambuena C, Yañez J, Flores V, Puentes P, Carrasco P, Villena R. Oral ketamine and midazolam for pediatric burn patients: A prospective, randomized, double-blind study. Journal of pediatric surgery. 2013;48(3):629-34.

29. Thompson EM, Andrews DD, Christ-Libertin C. Efficacy and safety of procedural sedation and analgesia for burn wound care. J Burn Care Res. 2012;33(4):504-9.

30. Canpolat DG, Esmaoglu A, Tosun Z, Akin A, Boyaci A, Coruh A. Ketamine-Propofol vs KetamineDexmedetomidine Combinations in Pediatric Patients Undergoing Burn Dressing Changes. Journal of Burn Care Research. 2012;33(6):718-22.

31. Karlow N, Schlaepfer CH, Stoll CRT, Doering M, Carpenter CR, Colditz GA, et al. A Systematic Review and Meta-analysis of Ketamine as an Alternative to Opioids for Acute Pain in the Emergency Department. Acad Emerg Med. 2018;25(10):1086-97.

32. Dolansky G, Shah A, Mosdossy G, Rieder M. What is the evidence for the safety and efficacy of using ketamine in children? Paediatr Child Health. 2008;13(4):307-8.

33. Kempf M, Kimble R, Cuttle L, editors The cytotoxicity of QV gentle wash compared to Chlorhexidine Gluconate on Primary human epidermal Keratinocyte (Hek) cells. Australia and New Zealand Burns Association, Annual Scientific Meeting 2017; Auckland, New Zealand.

34. Frear CC, Cuttle L, McPhail SM, Chatfield MD, Kimble RM, Griffin BR. Randomized clinical trial of negative pressure wound therapy as an adjunctive treatment for small-area thermal burns in children. Br J Surg. 2020;107(13):1741-50.

35. Taylor SC, Arsonnaud S, Czernielewski J. The Taylor Hyperpigmentation Scale: A new visual assessment tool for the evaluation of skin color and pigmentation. J Am Acad Dermatol. 2005;52(3):P170.

36. Harish V, Li Z, Maitz PKM. The optimal timing of outpatient Biobrane application for superficial and mid dermal partial thickness burns: Evidence for the '12-hour rule'. Burns. 2019;45(4):936-41.

37. Ter Horst B, Chouhan G, Moiemen NS, Grover LM. Advances in keratinocyte delivery in burn wound care. Adv Drug Deliv Rev. 2018;123:18-32. 
38. Salibian AA, Rosario ATD, Severo LAM, Nguyen L, Banyard DA, Toranto JD, et al. Current concepts on burn wound conversion-A review of recent advances in understanding the secondary progressions of burns. Burns. 2016;42(5):1025-35.

39. JanŽEkoviČ Z. A New Concept in the Early Excision and Immediate Grafting of Burns. The Journal of Trauma: Injury Infection Critical Care. 1970;10(12):1103-8.

40. Brown EA, De Young A, Kimble R, Kenardy J. Impact of Parental Acute Psychological Distress on Young Child Pain-Related Behavior Through Differences in Parenting Behavior During Pediatric Burn Wound Care. J Clin Psychol Med Settings. 2019;26(4):516-29.

41. Brown EA, Egberts M, Wardhani R, De Young A, Kimble R, Griffin B, et al. Parent and Clinician Communication During Paediatric Burn Wound Care: A Qualitative Study. Journal of Pediatric Nursing: Nursing Care of Children Families. 2020;55:147-54.

42. Heer IJ, Tiemeier H, Hoeks SE, Weber F. Intelligence quotient scores at the age of 6 years in children anaesthetised before the age of 5 years. Anaesthesia. 2017;72(1):57-62.

43. Rosenblatt A, Kremer M, Swanson B, Shah R. Anesthesia Exposure in the Young Child and Long-term Cognition: An Integrated Review. AANA J. 2019;87(3):231-42.

44. Shukla A, Chowdhary V. Neurodevelopmental outcome at 5 years of age after general anaesthesia or awake-regional anaesthesia in infancy (GAS): An international, multicentre, randomised, controlled equivalence trial. Acta Paediatr. 2019;108(11):2115-6.

45. Sun LS, Li G, Miller TLK, Salorio C, Byrne MW, Bellinger DC, et al. Association Between a Single General Anesthesia Exposure Before Age 36 Months and Neurocognitive Outcomes in Later Childhood. JAMA: the journal of the American Medical Association. 2016;315(21):2312-20.

46. Warner DO, Zaccariello MJ, Katusic SK, Schroeder DR, Hanson AC, Schulte PJ, et al. Neuropsychological and Behavioral Outcomes after Exposure of Young Children to Procedures Requiring General Anesthesia: The Mayo Anesthesia Safety in Kids (MASK) Study. Anesthesiology. 2018;129(1):89-105.

47. Racine NM, Riddell RR, Khan M, Calic M, Taddio A, Tablon P. Systematic Review: Predisposing, Precipitating, Perpetuating, and Present Factors Predicting Anticipatory Distress to Painful Medical Procedures in Children. J Pediatr Psychol. 2016;41(2):159-81.

48. Griffin BR, Frear CC, Babl F, Oakley E, Kimble RM. Cool Running Water First Aid Decreases Skin Grafting Requirements in Pediatric Burns: A Cohort Study of Two Thousand Four Hundred Ninety-five Children. Ann Emerg Med. 2020;75(1):75-85.

49. Wood FM, Phillips M, Jovic T, Cassidy JT, Cameron P, Edgar DW. Water First Aid Is Beneficial In Humans Post-Burn: Evidence from a Bi-National Cohort Study. PLoS One. 2016;11(1):e0147259. 50. 50 .

\section{Figures}




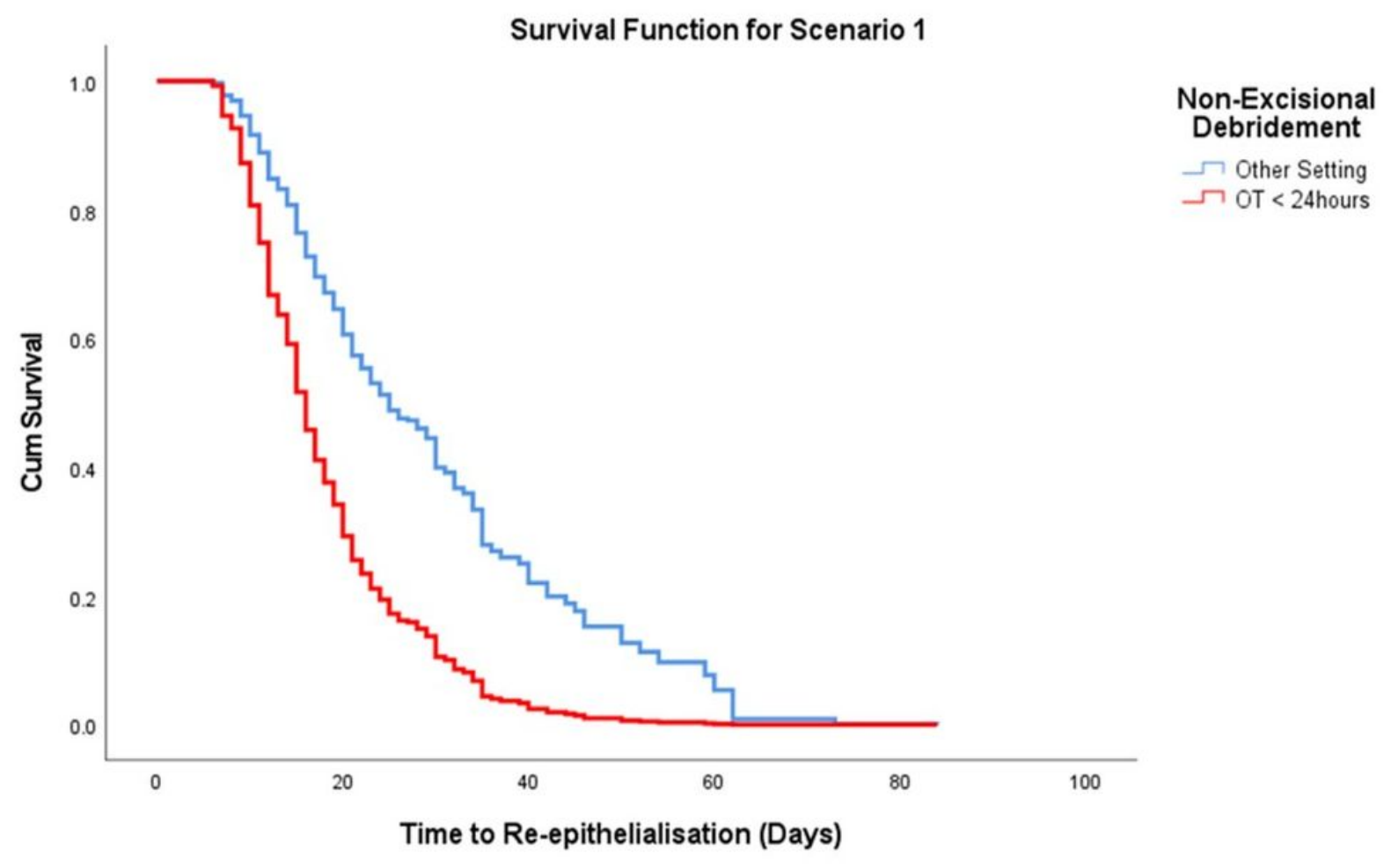

Figure 1

Effect of non-excisional debridement on re-epithelialisation time for Scenario 1 (OT<24hrs vs Other Settings)

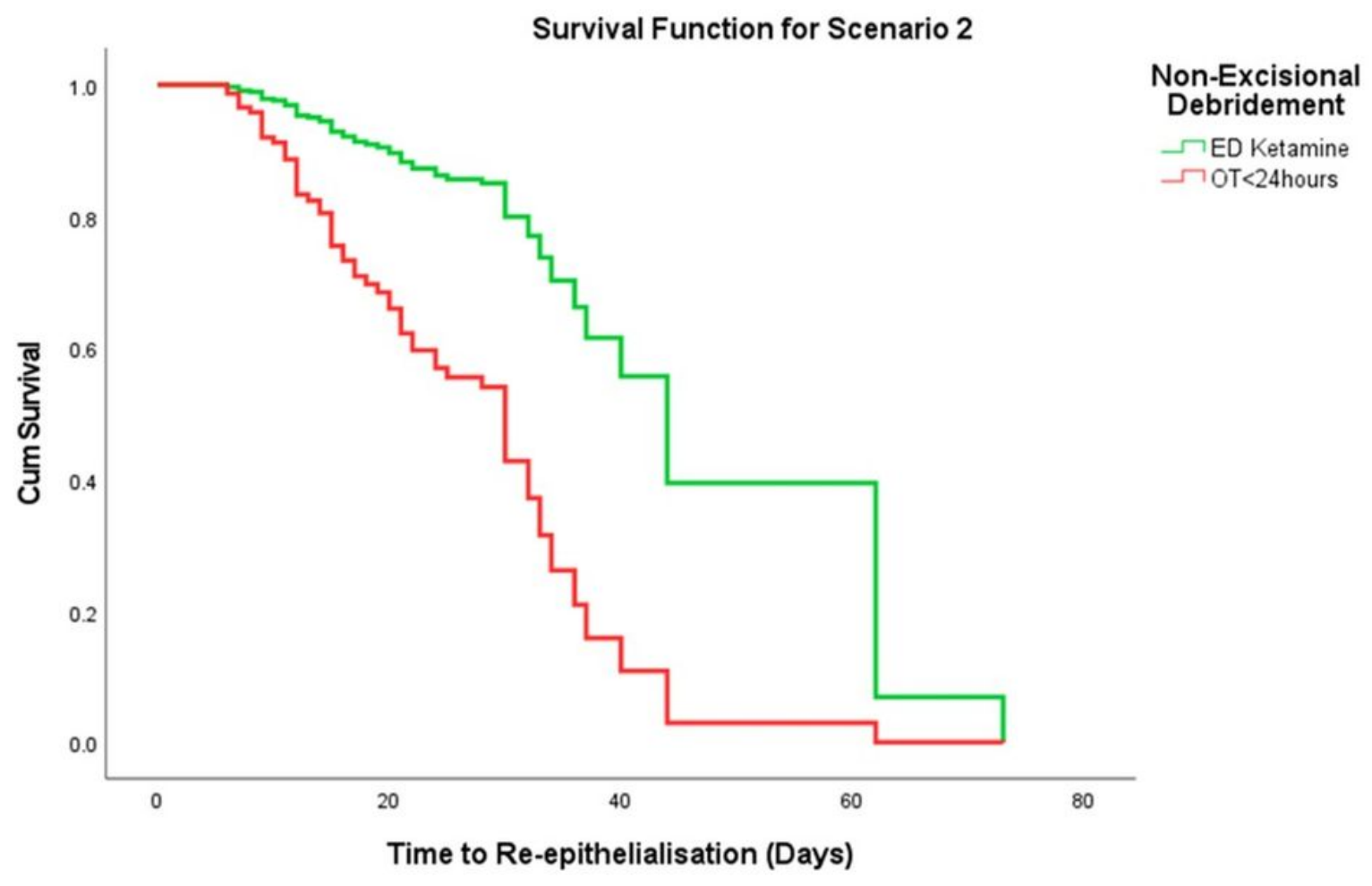

Page $17 / 18$ 
Figure 2

Effect of non-excisional debridement on re-epithelialisation time for Scenario 2 (OT<24hrs vs ED Ketamine) 